\title{
Dermocopy of erosive nipple adenoma
}

\section{Jihad Kassel, Zakia Douhi, Chaymae Jroundi, Hanane Baybay, Sara Elloudi, Fatima-Zahra Mernissi}

Department of Dermatology, University Hospital Hassan II, Fes, Morocco

Corresponding author: Jihad Kassel, MD, E-mail: kassel.jihad@gmail.com

Nipple Adenoma (NA) is a very uncommon, benign proliferative process of lactiferous ducts of the nipple first described by Jones in 1955. Clinically, it often presents as a unilateral and asymptomatic palpable nipple nodule, a visible nipple skin erosive lesion, and/or with discharge from the surface of the nipple skin. It is primarily seen in middle-aged women. Nipple adenoma can clinically mimic a mammary Paget's disease of the nipple [1]. The gold standard for making the most definitive final diagnosis of NA is histopathologic examination which shows a benign proliferation with a double cell component made up of bordering epithelial cells and peripheral myoepithelial cells [2]. Rare observations in the literature have focused on the interest of dermoscopy in the positive

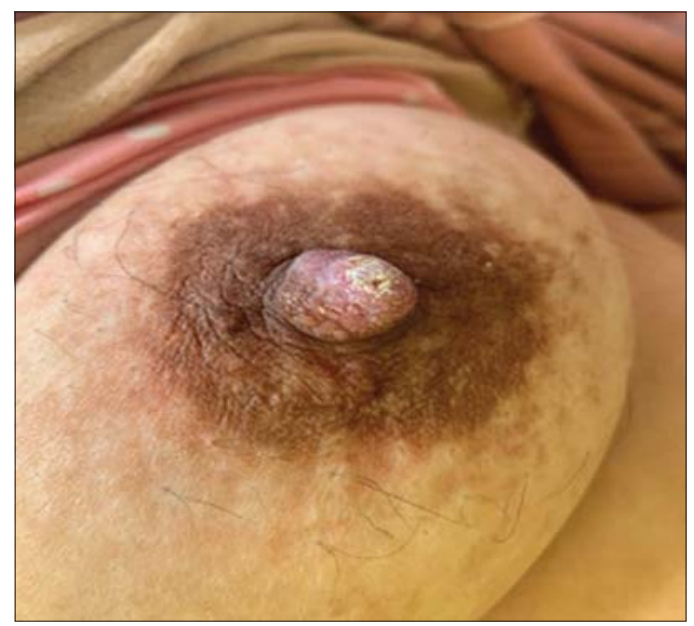

Figure 1: Clinical picture showing a nodular lesion on the right nipple diagnosis of NA, dermoscopic signs are structureless red areas and pink-white clods correspond to erosion and interspaced epidermis in histopathology, respectively. Red dots in linear, radial, semicircular patterns correlate with tubular and luminal openings in histopathologic studies. Red globules and red lines correspond to regular vessels of a benign tumor [3]. The treatment of choice for this pathology is that which ensures complete excision of the lesion and allowing plastic reconstruction of the nipple [1]. We describe a new case of dermoscopy of a Nipple adenoma.

A 34-year-old woman presented with a 2-year history of a nodular lesion on the right nipple, clinical

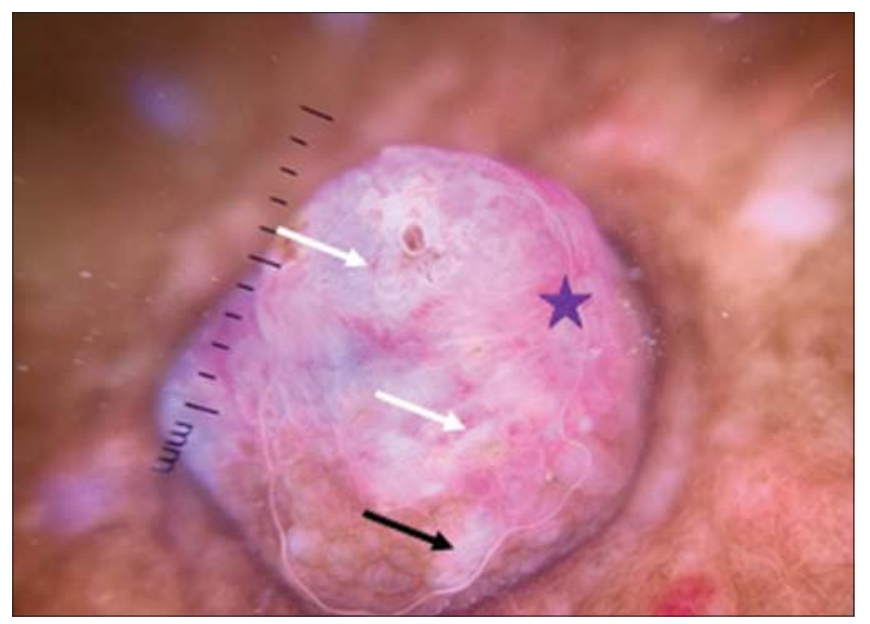

Figure 2: Dermoscopic picture showing: Pink-white clods (black arrow), red dots with pink background (purple asterisk). White and yellow hyperkeratotic scales (white arrows). 
examination showed a well-limited $5 \mathrm{~mm}$ nodule with eroded and hyperkeratotic surface. Dermoscopic examination revealed, pink-white clods, red dots with pink background and yellow hyperkeratotic scales. Histopathologic study was compatible with NA.

\section{Consent}

The examination of the patient was conducted according to the principles of the Declaration of Helsinki.

The authors certify that they have obtained all appropriate patient consent forms, in which the patients gave their consent for images and other clinical information to be included in the journal. The patients understand that their names and initials will not be published and due effort will be made to conceal their identity, but that anonymity cannot be guaranteed.

\section{REFERENCES}

1. Erosive Adenomatosis of the Nipple: A Clinical Diagnostic Challege Clin Cosmet Investig Dermatol. 2020;13:587590.

2. Spohn GP, Trotter SC, Tozbikian G, Povoski SP. Nipple adenoma in a female patient presenting with persistent erythema of the right nipple skin: case report, review of the literature, clinical implications, and relevancy to health care providers who evaluate and treat patients with dermatologic conditions of the breast skin. BMC Dermatol. 2016;16:4.

3. Ansari MS, Taghizadeh Fazli J, Ehsani A. Dermoscopy of nipple adenoma. Clin Case Rep. 2020;00:1-3.

Copyright by Jihad Kassel, et al. This is an open access article distributed under the terms of the Creative Commons Attribution License, which permits unrestricted use, distribution, and reproduction in any medium, provided the original author and source are credited.

Source of Support: Nil, Conflict of Interest: None declared. 